\title{
Atributos químicos e físicos de um Argissolo Vermelho-Amarelo Distrófico sob plantio direto
}

\section{Chemical and physical attributes of a Udult under no-tillage}

\author{
Silvane de Almeida Campos, Caetano Marciano de Souza, João Carlos Cardoso Galvão, Júlio César Lima \\ Neves
}

Universidade Federal de Viçosa, UFV, Departamento de Fitotecnia, Rua Dr. Milton Bandeira, 115 apto 202, Centro, Viçosa, MG, 36570-000, email: silvaneacampos@yahoo.com.br

\author{
Recebido em:12/09/2017_ Aceito em:02/03/2017
}

\begin{abstract}
Resumo. O plantio direto é uma técnica tradicionalmente adotada no Brasil, sendo necessária a sua utilização na agricultura orgânica. Assim, realizou-se este estudo com o objetivo de determinar os atributos químicos e físicos de um Argissolo Vermelho-Amarelo Distrófico sob plantio direto em diferentes sistemas de manejo . O delineamento estatístico adotado foi blocos casualizados, com três repetições, em esquema fatorial 3 × 2 compreendendo três áreas: plantio direto (PD), plantio direto diferenciado (PDD) e mata nativa $(\mathrm{MN})$, e duas profundidades de amostragem do solo (0-0,20 e 0,20-0,40 m). O plantio direto diferenciado refere-se às parcelas que receberam o manejo orgânico. As amostras de solo foram coletadas para a determinação dos atributos químicos [ $\mathrm{pH}$ em água, teores de matéria orgânica do solo (MOS) e de $\mathrm{Zn}, \mathrm{Cu}$, $\mathrm{Mn}, \mathrm{Fe}, \mathrm{B}$ ] e físicos [densidade do solo (DS), argila dispersa em água (ADA), índice de floculação (IF), umidade na capacidade de campo (CC) e no ponto de murcha permanente (PMP), capacidade de água disponível (CAD) e classe textural]. Os atributos químicos avaliados, com exceção do Zn $(0-0,20 \mathrm{~m})$, apresentaram comportamento similar para as áreas de PD e PDD, independente da profundidade amostrada. O sistema plantio direto favoreceu a manutenção do teor de MOS, sendo equivalente à MN. Com relação às condições físicas, os sistemas PD e PDD preservaram a estrutura solo próxima as condições da MN, não havendo compactação nestas áreas. Tais sistemas apresentaram maior disponibilidade de água para as plantas em comparação a área preservada, nas duas profundidades.
\end{abstract}

Palavras-chave: física do solo, manejo do solo, química do solo.

Abstract. No-tillage is a technique traditionally used in Brazil, being necessary for its use in organic agriculture. Thus the present study had as objective of determine the chemical and physical attributes of a Udult under no-tillage in different management systems. The statistical design was randomized in blocks, with three replications, in a factorial $3 \times 2$ comprising three areas: no-tillage, differentiated no-tillage and native forest, we were sampling two soil depths (0-0.20 and 0.20-0.40 m)The differentiated no-tillage refers to the parcels that received the organic management. to determine chemical attributes $[\mathrm{pH}$ in water, soil organic matter $(\mathrm{SOM}), \mathrm{Zn}, \mathrm{Cu}, \mathrm{Mn}, \mathrm{Fe}, \mathrm{B}$ ] and physical [soil bulk density, clay dispersed in water, flocculation index, field capacity, permanent wilting point, available water capacity and particle size distribution]. The chemical attributes evaluated with the exception of $\mathrm{Zn}(0-0.20 \mathrm{~m})$, submitted behavior similar for no-till and no-till organic areas, independent the depth sampled. The no-tillage system favors maintaining the organic matter content in the soil it is equivalent to the native forest. With respect to physical conditions, the systems no-tillage and differentiated no-tillage preserved soil bulk density similarly to the native forest, without compression in these areas. Such systems presented greater water availability to the plants compared to the preserved area in the two depths.

Keywords: chemical soil, management soil, physical soil.

\section{Introdução}

$\mathrm{O}$ plantio direto constitui um sistema eficiente no controle de erosão e tem sido utilizado cada vez em maior escala, especialmente, em áreas com culturas anuais e sujeitas à ação dos processos erosivos, visando 
não só obter altas produtividades, mas assegurar a sustentabilidade agrícola dos solos (Sherer et al., 2007). Tornou-se importante instrumento para a manutenção e mesmo a recuperação da capacidade produtiva de solos manejados convencionalmente e de áreas degradadas (Torres et al., 2008).

No Brasil, aproximadamente 32 milhões de hectares foram cultivados sob sistema plantio direto (SPD) na safra 2011/2012 (FEBRAPDP, 2012). Este sistema proporciona o acúmulo de resíduos vegetais em superfície, resultando no aumento do teor de matéria orgânica na superfície do solo (Andrade et al., 2009) que influencia diretamente seus atributos físicos, químicos e biológicos (Nicoloso et al., 2008). Por sua vez, o aumento da matéria orgânica altera o $\mathrm{pH}$ do solo, a toxidez por alumínio e a dinâmica dos nutrientes (Anghinoni, 2007). A MOS é influenciada pelo manejo adotado, sendo por esta razão, considerada um indicador da qualidade do solo e sustentabilidade de agroecossistemas (Machado et al., 2014).

A fertilidade é um dos fatores que pode sofrer modificações favoráveis ou desfavoráveis em função do uso e manejo do solo (Wastowski et al., 2010). Desta forma, o conhecimento da dinâmica dos nutrientes no solo a partir da superfície, local em que os fertilizantes são depositados em áreas de plantio direto, merece especial atenção, para estabelecer ajustes na recomendação de fertilizantes e corretivos (Scherer et al., 2007) com possibilidade de redução futura do uso destes e de poluição, criando condições favoráveis para o cultivo por longos períodos sem exaurir o solo (Matias et al., 2009).

Os efeitos do SPD nas propriedades químicas do solo como teor de matéria orgânica, $\mathrm{pH}$ e macronutrientes são relativamente bem conhecidos (Frazão et al., 2008; Wastowski et al., 2010; Cunha et al., 2011; Martínez et al., 2013). No entanto, há carência de informações a respeito da dinâmica de micronutrientes em solos brasileiros quando manejados sob SPD, embora estes sejam essenciais para as plantas assim como os macronutrientes.

O levantamento dos atributos químicos do solo pode auxiliar na identificação de problemas intrínsecos ao solo da região ou do seu manejo (Yagi et al., 2011). Com este enfoque, na literatura encontram-se diversos trabalhos que avaliam atributos químicos e físicos de solo sob SPD em comparação a outros sistemas de cultivo, notadamente, o plantio convencional (Wastowski et al., 2010; Lourente et al., 2011; Wyngaard et al. 2012; Calegari et al., 2013; Oliveira et al., 2015;
Sales et al., 2016). Entretanto, há poucos estudos que avaliam as propriedades do solo em condições de SPD submetido a diferentes manejos.

O manejo adequado dos solos cultivados é de extrema importância a fim de manter ou alterar o mínimo possível as suas propriedades físicas, mantendo-as satisfatórias ao bom desenvolvimento das culturas. A modificação destas propriedades pode ocasionar problemas tais como compactação, redução na infiltração de água no solo, na retenção de água, na porosidade e na agregação (Pereira Junior et al., 2010).

A maioria dos estudos na literatura aponta para maior armazenagem e disponibilidade de água às plantas em solo sob SPD (Vita et al., 2007; Zanette et al., 2007; Dalmago et al., 2009) constatado, notadamente, em sistemas que apresentam mais tempo de uso e em camadas próximas à superfície. Em vista da dificuldade de se caracterizar na prática todos os fatores envolvidos na disponibilidade de água para as plantas, a capacidade de campo e o ponto de murcha permanente prevalecem nos estudos de física do solo e irrigação (Ramos et al., 2013).

Com base no exposto, objetivou-se avaliar alguns atributos químicos e físicos de um Argissolo Vermelho-Amarelo Distrófico sob plantio direto em diferentes sistemas de manejo.

\section{Material e métodos}

A amostragem do solo ocorreu no final do período chuvoso (abril/2015), na Estação Experimental São João, pertencente à Universidade Federal de Viçosa, situada em Coimbra, MG, com localização geográfica de $20^{\circ} 49^{\prime} 37^{\prime \prime S}$ e $42^{\circ} 45^{\prime} 58^{\prime \prime O}$ e $719 \mathrm{~m}$ de altitude. O solo é classificado como Udult, fase terraço, textura muito argilosa (Embrapa, 2013).

$\mathrm{O}$ delineamento experimental adotado foi um fatorial $3 \times 2$ com blocos ao acaso, com três repetições, compreendendo três áreas: (I) fragmento de mata nativa (MN) com cobertura vegetal secundária pertencente à Mata Atlântica, utilizado como referência; (II) Plantio Direto (PD) e (III) Plantio Direto Diferenciado (PDD) ambos consolidados, 13 anos de implantação, e duas profundidades de amostragem do solo (0-0,20 e 0,20-0,40 m).

Cada repetição foi composta por quinze sub-amostras de solo, retiradas aleatoriamente em cada área avaliada, utilizando-se trado tipo Sonda. No momento da amostragem do solo, as áreas sob plantio direto se encontravam em pousio.

$\mathrm{Na}$ área de PD, realizou o cultivo de milho para produção de grãos no verão e de feijão no inverno. Quando necessário, fez a calagem com base na análise química do solo, com aplicação de 
calcário dolomítico a lanço na superfície, sendo este incorporado com grade leve. Para formação da palhada, efetuou a dessecação química, aplicando 2,5 $\mathrm{L} \mathrm{ha}^{-1}$ do glifosato $360 \mathrm{~g} \mathrm{~L}^{-1}$ do equivalente ácido na vegetação espontânea da área agrícola que se encontrava em pousio por seis meses, sendo permanentemente mantida em sistema de plantio direto. Sete dias após a aplicação do dessecante foi feita a semeadura da cultura (milho ou feijoeiro).

$\mathrm{Na}$ adubação de plantio utilizou a fórmulaNPK 08-28-16 enriquecido com Zn e B e em cobertura, ureia, sendo estes adubos aplicados ao lado da linha de plantio, na dose recomendada para cada cultura. O controle de plantas daninhas foi feito com herbicida pós-emergente na entrelinha da cultura. No caso do milho, a irrigação suplementar foi feita apenas na fase vegetativa, quando necessária. Após a colheita, os resíduos culturais foram mantidos sobre a superfície do solo.

$\mathrm{Na}$ área de PDD, efetuou-se a calagem por ocasião do estabelecimento do sistema, há 13 anos, utilizando $1,5 \mathrm{t} \mathrm{ha}^{-1}$ de calcário dolomítico a lanço na superfície do solo (Mg 13\% na composição), sendo incorporado com grade leve. Realizou o cultivo de aveia preta (Avena strigosa Schreb), semeada a lanço e irrigada, para fornecimento de palhada, sendo manejada mecanicamente com roçadeira costal motorizada e exposta à dessecação natural. Após a dessecação, realizou a semeadura do milho consorciado com feijão de porco (Canavalia ensiformis) na linha, sendo o feijão de porco semeado com matraca na densidade de seis plantas por metro. A adubação é feita em dose única logo após a semeadura, empregando-se $40 \mathrm{~m}^{3} \mathrm{ha}^{-1}$ de composto orgânico distribuído sobre o sulco de semeadura. O composto orgânico foi produzido a partir de restos culturais de sorgo e esterco bovino, e apresentou os teores de minerais $157,29.715,715,33$ e 25 $\left(\mathrm{mg} \mathrm{kg}^{-1}\right)$ de $\mathrm{Zn}, \mathrm{Fe}, \mathrm{Mn}, \mathrm{Cu}$ e B, respectivamente, por ocasião da última aplicação na área, realizada em outubro de 2012. O controle de plantas espontâneas é feito com duas roçadas na entrelinha do milho. As culturas recebem irrigação suplementar durante a fase vegetativa do milho, quando necessário. Os resíduos da colheita permanecem distribuídos na superfície do solo.

Foram coletadas nas camadas $0-0,20 \mathrm{~m}$ e 0,20-0,40 $\mathrm{m}$ amostras deformadas de solo para determinação de $\mathrm{pH}$ em água, teores de matéria orgânica do solo (MOS), zinco $(\mathrm{Zn})$, cobre $(\mathrm{Cu})$, manganês $(\mathrm{Mn})$, ferro $(\mathrm{Fe})$ e boro $(\mathrm{B})$, argila dispersa em água (ADA), índice de floculação (IF) e classe textural. Amostras indeformadas foram coletadas para determinar a umidade na capacidade de campo (CC) e no ponto de murcha permanente (PMP), capacidade de água disponível (CAD) e densidade do solo (DS).

$\mathrm{O}$ pH em água na relação 1:2,5 (solo-água) foi determinado conforme Embrapa (2013) e a matéria orgânica do solo segundo a metodologia de Walkley-Black para extração do carbono orgânico (Embrapa, 1997), sendo este multiplicado pelo fator 1,724 . Os minerais foram extraídos em solução bi ácida (ácido clorídrico $0,05 \mathrm{~N}+$ ácido sulfúrico $0,5 \mathrm{~N}$ ) e as determinações feitas por espectrofotometria de absorção atômica (CFSEMG, 1999).

$\mathrm{O}$ teor de argila dispersa em água foi determinado pelo método da pipeta, suprimindose o uso do dispersante químico (Embrapa, 1997). De posse dos valores de argila total (AT) e ADA foi calculado o índice de floculação (\%) pela equação: $\mathrm{IF}=100 \times(\mathrm{AT}-\mathrm{ADA}) / \mathrm{AT}$.

Considerou-se como capacidade de campo a umidade do solo correspondente à tensão de -10 $\mathrm{kPa}$ e, como ponto de murcha permanente, a umidade do solo correspondente à tensão de -1500 $\mathrm{kPa}$, ambos determinados pelo método. A capacidade de água disponível foi determinada pela diferença entre a umidade na capacidade de campo e no ponto de murcha permanente conforme Embrapa (2013).

Para obtenção da classe textural procedeuse a análise granulométrica determinada pelo método da pipeta e a classificação propostos pela Embrapa (1997).

Determinou-se a densidade do solo pelo método do anel volumétrico com capacidade de $98,0 \mathrm{~cm}^{3}$, sendo os anéis coletados com trado tipo Uhland.

Os dados foram submetidos à análise de variância por meio do programa ASSISTAT e as médias dos tratamentos comparadas pelo teste de Tukey a $5 \%$ de probabilidade (Silva e Azevedo, 2009).

\section{Resultados e discussão}

Para os atributos químicos estudados, não houve interação significativa entre áreas $\mathrm{e}$ profundidades (Tabela 1). 
Tabela 1. pH em água (1:2,5), matéria orgânica do solo (MOS), zinco $(\mathrm{Zn})$, cobre $(\mathrm{Cu})$, manganês $(\mathrm{Mn})$, ferro (Fe) e boro (B) de Argissolo Vermelho-Amarelo sob plantio direto (PD) e plantio direto diferenciado (PDD) comparados à mata nativa (MN), em diferentes profundidades. Coimbra-MG, 2015

\begin{tabular}{|c|c|c|c|}
\hline \multirow{2}{*}{ Área } & \multicolumn{3}{|c|}{ Profundidades (m) } \\
\hline & $0-0,20$ & & $0,20-0,40$ \\
\hline & & H em água $(1: 2,5)$ & \\
\hline $\mathrm{MN}$ & $4,55 \mathrm{bA}$ & & $4,55 \mathrm{bA}$ \\
\hline PD & $5,70 \mathrm{aA}$ & & $5,40 \mathrm{aB}$ \\
\hline \multirow[t]{2}{*}{ PDD } & $5,70 \mathrm{aA}$ & & $5,50 \mathrm{aB}$ \\
\hline & & MOS, dag $\mathrm{kg}^{-1}$ & \\
\hline $\mathrm{MN}$ & $3,41 \mathrm{aA}$ & & $2,92 \mathrm{aB}$ \\
\hline $\mathrm{PD}$ & $3,54 \mathrm{aA}$ & & $2,46 \mathrm{aB}$ \\
\hline \multirow[t]{2}{*}{ PDD } & $3,66 \mathrm{aA}$ & & $2,80 \mathrm{aB}$ \\
\hline & & $\mathrm{Zn}, \mathrm{mg} \mathrm{dm}^{-3}$ & \\
\hline $\mathrm{MN}$ & $1,25 \mathrm{cA}$ & & $2,05 \mathrm{aA}$ \\
\hline PD & $9,15 \mathrm{aA}$ & & $2,20 \mathrm{aB}$ \\
\hline \multirow[t]{2}{*}{ PDD } & $7,10 \mathrm{bA}$ & & $2,40 \mathrm{aB}$ \\
\hline & & $\mathrm{Cu}, \mathrm{mg} \mathrm{dm}^{-3}$ & \\
\hline $\mathrm{MN}$ & $0,65 \mathrm{bA}$ & & $1,05 \mathrm{bA}$ \\
\hline $\mathrm{PD}$ & $2,15 \mathrm{aA}$ & & $2,55 \mathrm{aA}$ \\
\hline \multirow[t]{2}{*}{ PDD } & $2,25 \mathrm{aA}$ & & $2,15 \mathrm{aA}$ \\
\hline & & $\mathrm{Mn}, \mathrm{mg} \mathrm{dm}^{-3}$ & \\
\hline MN & $22,00 \mathrm{bA}$ & & $11,90 \mathrm{bB}$ \\
\hline PD & $82,25 \mathrm{aA}$ & & $28,85 \mathrm{aB}$ \\
\hline \multirow[t]{2}{*}{ PDD } & $74,80 \mathrm{aA}$ & & $31,40 \mathrm{aB}$ \\
\hline & & $\mathrm{Fe}, \mathrm{mg} \mathrm{dm}^{-3}$ & \\
\hline $\mathrm{MN}$ & $69,20 \mathrm{aA}$ & & $90,15 \mathrm{aA}$ \\
\hline $\mathrm{PD}$ & $49,95 \mathrm{bA}$ & & $38,40 \mathrm{bA}$ \\
\hline \multirow[t]{2}{*}{ PDD } & $57,45 \mathrm{bA}$ & & $39,55 \mathrm{bA}$ \\
\hline & & $\mathrm{B}, \mathrm{mg} \mathrm{dm}^{-3}$ & \\
\hline $\mathrm{MN}$ & $0,30 \mathrm{aA}$ & & $0,25 \mathrm{aA}$ \\
\hline $\mathrm{PD}$ & $0,40 \mathrm{aA}$ & & $0,25 \mathrm{aB}$ \\
\hline PDD & $0,30 \mathrm{aA}$ & & $0,30 \mathrm{aA}$ \\
\hline
\end{tabular}

Os valores seguidos da mesma letra minúscula na coluna e maiúscula para as profundidades não diferem estatisticamente pelo teste de Tukey, a 5\% de probabilidade.

Os valores de $\mathrm{pH}$ em água não diferiram nas áreas de PD e PDD, mas apresentaram diferença em relação à $\mathrm{MN}$, com decréscimo significativo em profundidade, estando os valores adequados aos cultivos (Tabela 1). No PD, este resultado pode ser atribuído à correção da acidez do solo através de corretivos e a complexação de Fe pela matéria orgânica presente, enquanto que, no PDD, apenas por este último. Nas áreas cultivadas, independentemente do manejo adotado, os maiores valores foram encontrados na camada $0-0,20 \mathrm{~m}$ do solo devido a pouca mobilidade de carbonatos aplicados superficialmente. $\mathrm{O} \mathrm{pH}$ em água da $\mathrm{MN}$ evidencia a acidez elevada dos solos da região, uma vez que este ambiente não recebeu calagem. Calegari et al.
(2013) também verificaram que o $\mathrm{pH}\left(\mathrm{CaCl}_{2}\right)$ de um Latossolo Vermelho Aluminoférrico sob plantio direto apresentou maior valor em comparação à mata utilizada como controle e Barbosa et al. (2012) constataram variação nos valores de $\mathrm{pH}\left(\mathrm{CaCl}_{2}\right)$ entre as profundidades de 0-0,20 e 0,20-0,40 m, em Latossolo Vermelho cultivado com milho em SPD.Os teores de MOS não variaram entre as áreas estudadas, porém reduziram significativamente com a profundidade do solo (Tabela 1), o que denota que as áreas agrícolas estão conservadas semelhantemente à $\mathrm{MN}$, assim, as práticas foram benéficas ao sistema de cultivo. Tal resultado se justifica pelo grande aporte de resíduo orgânico em superfície propiciado pelo SPD, aliado ao mínimo revolvimento do solo, o que pode ocasionar 
acúmulo de carbono no seu perfil (Campos et al., 2011) e, consequentemente, de MOS. O teor de MOS está associado, entre outros fatores, a quantidade e qualidade de resíduos vegetais depositados ao solo, sobretudo, a relação $\mathrm{C} / \mathrm{N}$ e constituintes mais recalcitrantes à decomposição microbiana como ligninas, ceras e compostos fenólicos de alto peso molecular (Correia e Durigan, 2008). Segundo Carneiro et al. (2009) na mata, a MOS encontra-se preservada, devido a não mobilização do solo e a constante reciclagem do material vegetal proporcionada pela maior diversidade de espécies presentes. De modo semelhante, Lourente et al. (2011) não observaram diferença nos teores de MOS de um Latossolo Vermelho distroférrico sob plantio direto e vegetação nativa usada como referência e Barbosa et al. (2012) encontraram diferença no conteúdo de MOS nas profundidades $0-0,20$ e 0,20-0,40 m de um Latossolo Vermelho cultivado com milho em SPD, com maiores valores na camada superficial.

Os níveis de $\mathrm{Zn}$ se diferenciaram entre as áreas estudadas apenas na camada de 0-0,20 $\mathrm{m}$ do solo, registrando redução significativa entre profundidades nas áreas sob plantio direto (Tabela 1). O Zn normalmente apresenta-se em maior deficiência nos solos brasileiros, tanto para culturas temporárias quanto perenes (Malavolta, 2006), fato não constatado no presente estudo. Os teores de $\mathrm{Zn}$ verificados nas áreas de plantio direto, na profundidade $0-0,20 \mathrm{~m}$ do solo, se devem ao efeito residual da adubação de plantio das culturas na superfície do solo. A diferença existente entre PD e PDD se baseia na maior liberação de $\mathrm{Zn}$ pelo adubo formulado 08-28-16 associada à frequente deposição de calcário que também é fonte deste nutriente no ambiente PD em relação à disponibilidade de $\mathrm{Zn}$ pelo composto orgânico produzido com esterco bovino no ambiente PDD. Jakelaitis et al. (2008) também observaram que os valores de $\mathrm{Zn}$ na área cultivada com milho em SPD foi maior do que no solo sob mata no perfil analisado $(0-0,10 \mathrm{~m})$ de um Argissolo Vermelho-Amarelo. Barbosa et al. (2012) encontraram diferença nos teores de $\mathrm{Zn}$ nas profundidades de 0-0,20 e 0,20-0,40 $\mathrm{m}$ de um Latossolo Vermelho cultivado com milho em SPD, com maiores valores na camada menos profunda do solo.

Os teores de $\mathrm{Cu}$ não variaram entre as áreas de PD e PDD, mas diferiram significativamente do ambiente de MN. Com relação às profundidades estudadas, os valores se apresentaram homogêneos para todas as áreas (Tabela 1). Os níveis de $\mathrm{Cu}$ observados nas áreas de plantio direto podem ser explicados pela mineralização da MOS remanescente e pela adição de calcário no PD e de composto no PDD. Em contrapartida, Jakelaitis et al. (2008) não notaram diferença nos níveis de $\mathrm{Cu}$ nos ambientes de cultivo de milho em SPD e de mata, na camada superficial avaliada $(0-0,10 \mathrm{~m})$ de um Argissolo Vermelho-Amarelo e Barbosa et al. (2012) observaram diferença nos teores de $\mathrm{Cu}$ nas profundidades $0-0,20$ e $0,20-0,40 \mathrm{~m}$ de um Latossolo Vermelho cultivado com milho em SPD, apresentando níveis mais elevados na maior profundidade do solo. Já Scherer et al. (2010) também observaram que os solos sob MN apresentaram teores mais baixos de $\mathrm{Cu}$ na camada superficial $(0-0,05 \mathrm{~m})$ em relação às camadas subjacentes no mesmo perfil de áreas com culturas anuais sob plantio direto.

Não se detectou diferença nos teores de Mn das áreas sob PD e PDD, as quais diferenciaram em relação à área sob $\mathrm{MN}$, com redução significativa entre as profundidades analisadas (Tabela 1). Nota-se elevados teores de Mn, sobretudo, nas áreas de plantio direto no perfil 0$0,20 \mathrm{~m}$ do solo, fato que deve estar relacionado a efetivação dos ambientes cultivados na fase terraço, onde comumente se verifica acúmulo de $\mathrm{Mn}$, o que não ocorre na $\mathrm{MN}$ que se encontra no topo do terreno, não tendo efeito do manejo. Resultado similar ao do presente estudo foi observado por Barbosa et al. (2012) encontrando diferença nos teores de $\mathrm{Mn}$ nas profundidades 00,20 e $0,20-0,40 \mathrm{~m}$ de um Latossolo Vermelho cultivado com milho em SPD, com obtenção de maiores teores na camada próxima à superfície.

Não foram constatadas diferenças nos teores de Fe nas áreas de PD e PDD, entretanto, estas se diferiram em comparação à MN. Observase ainda que os teores não variaram significativamente com as profundidades (Tabela 1). Altos valores de $\mathrm{Fe}$ foram observados, notadamente, no ambiente de $\mathrm{MN}$, nas duas profundidades amostradas, indicando a presença de minerais ricos neste elemento na constituição do material de origem do solo. Além disso, é comum ocorrer maior disponibilidade de $\mathrm{Fe}$ em solos mais ácidos, o que se observa na $\mathrm{MN}$. Na camada 0-0,20 $\mathrm{m}$ do solo, onde se emprega o SPD, menores valores foram obtidos quando comparados à $\mathrm{MN}$, devido à elevação do $\mathrm{pH}$ promovida pela correção no ambiente agrícola, não realizada no ambiente natural. A redução da acidez do solo diminui a disponibilidade de minerais como $\mathrm{Zn}, \mathrm{Mn}, \mathrm{Cu}$ e Fe (Sousa et al., 2007), o que se observou exclusivamente para o Fe neste trabalho. Barbosa et al. (2012) verificaram que o teor de $\mathrm{Fe}$ não alterou nas 
camadas 0-0,20 e 0,20-0,40 $\mathrm{m}$ de um Latossolo Vermelho cultivado com milho em SPD.

Nas áreas estudadas não foi verificada diferença significativa nas concentrações de B, porém nota-se redução da sua disponibilidade entre as profundidades apenas na área de PD (Tabela 1). De modo geral, o B apresenta-se em maior deficiência nos solos brasileiros, para culturas temporárias e perenes. Normalmente os maiores teores de $\mathrm{B}$ total e disponível são encontrados nas camadas superficiais onde há maior teor de MOS (Malavolta, 2006). No entanto, este comportamento não foi verificado, uma vez que na camada $0-0,20 \mathrm{~m}$ do solo, onde se constatou os maiores teores de MOS, foram encontrados baixos teores de $\mathrm{B}$, com exceção do PD. Isto se deve, possivelmente, ao maior fornecimento de $\mathrm{B}$ pelo adubo químico adicionado ao solo durante a semeadura do milho e feijão, de modo superficial. Os baixos teores verificados podem ser explicados pela menor retenção de $\mathrm{B}$ na fase sólida do solo, o qual fica retido em argila silicatada e MOS, fato que pode justificar essa proximidade dos teores de $\mathrm{B}$ nas áreas avaliadas. Zanão Júnior et al. (2007) não encontraram diferença significativa nos valores de $\mathrm{B}$ entre as profundidades $0-0,10,0,10-0,20$ e $0-0,20$ m num Latossolo Vermelho distrófico sob sistema plantio direto por oito anos.

Houve interação entre as áreas e profundidades para as características físicas avaliadas, com exceção da DS, IF e classe textural (Tabela 2).Os valores de DS variaram de 1,04 e $1,17 \mathrm{~g} \mathrm{~cm}^{-3}$ não se diferindo entre ambientes e entre profundidades (Tabela 2) podendo ser considerados adequados para um bom desenvolvimento radicular das plantas. Tais resultados contradizem, em parte, a tendência de maior DS em plantio direto próximo a superfície (Luciano et al., 2010; Wendling et al., 2012). Os valores observados podem ser atribuídos ao conteúdo de MOS, que contribuiu para redução da DS em longo prazo por proporcionar maior agregação do solo. Sales et al. (2016) observaram que o sistema de plantio direto manteve a agregação do solo de modo semelhante à mata nativa. Segundo Mazurana et al. (2011) a redução da DS pode estar associada à atuação dos diferentes sistemas radiculares das culturas que exploram as camadas do solo e quando senescem deixam no solo espaços ocupados pelas raízes, contribuindo para o aumento da porosidade total e, consequente, diminuição da DS. A palha e as raízes das plantas serão transformadas em MOS, que, associada à sua fração mineral, atua na estruturação do solo e, por consequência, reduz a sua densidade. Além disso, a MOS pode elevar o volume de poros, favorecendo a infiltração e aeração para desenvolvimento das plantas (Jordan et al., 2010; Cunha et al., 2011). Jakelaitis et al. (2008) verificaram valores de DS semelhantes aos deste estudo, avaliando um Argissolo VermelhoAmarelo cultivado com milho em SPD por cinco anos. Lourente et al. (2011) também não verificaram efeito dos sistemas de manejo avaliados sobre a densidade de um Latossolo Vermelho Distroférrico típico que variou entre 1,10 e $1,14 \mathrm{~g} \mathrm{~cm}^{-3}$.

Os valores de ADA em PD e PDD foram iguais e superiores aos encontrados no solo com $\mathrm{MN}$, expressivamente, na camada $0-0,20 \mathrm{~m}$ (Tabela 2) o que pode indicar uma maior movimentação de argila nesta camada do solo, provavelmente devido ao revolvimento superficial nas áreas sob SPD que, embora seja mínimo, não é praticado no ecossistema mata. A realização de calagem, aplicação de fertilizantes, a exposição do solo a ciclos de umedecimento e secagem, a menor proteção dos solos em SPD em comparação à $\mathrm{MN}$ contribuíram para a maior dispersão de argilas. Os baixos valores de ADA verificados nos três ambientes avaliados pode se atribuir à efetividade do sistema de plantio direto em manter as características físicas do solo. Já Marasca et al. (2013) não detectaram diferença estatística na quantidade de ADA das áreas sob SPD e MN para todas as profundidades estudadas, com exceção da profundidade $0,10-0,20 \mathrm{~m}$. Para as áreas cultivadas, os maiores valores observados na camada de 0-0,20 m devem-se à ação do disco de semeadura e à deposição de fertilizantes que contribuem para a dispersão das partículas de argila do solo. De maneira similar, Almeida et al. (2014) observaram que o valor de ADA de um Latossolo Amarelo cultivado com milho em SPD e sob Cerrado natural não se diferenciou, com menor dispersão de argila na camada $0-0,20 \mathrm{~m}$. Os autores observaram que no ambiente com o milho os agregados do solo foram distribuídos em tamanhos uniformes, colaborando para este resultado.

O IF das argilas não apresentou diferença significativa entre áreas e entre profundidades, verificando-se valores de 99,9\% (Tabela 2). O elevado IF constatado nas áreas em estudo mostra a efetividade do plantio direto em manter as características do solo mais próximas do ambiente natural. Almeida et al. (2014) notaram que o IF de um Latossolo Amarelo sob Cerrado natural foi maior que sob pastagem, milho cultivado em SPD e eucalipto, na camada $0-0,20 \mathrm{~m}$. Porém, na camada 0,20-0,40 m, a área sob SPD apresentou maior IF do solo comparativamente às demais áreas.

Campos et al., v.11, n.41, p. 230-240, Dourados, 2018 
Com relação à $\mathrm{CC}$ a diferença foi significativa entre áreas e profundidades estudadas, sendo maior em PDD em relação ao PD e MN (Tabela 2).

Tabela 2. Densidade do solo (DS), argila dispersa em água (ADA), índice de floculação (IF), umidade na capacidade de campo (CC) e no ponto de murcha permanente (PMP), capacidade de água disponível (CAD) e classe textural (argila total, silte e areia) de um Argissolo Vermelho-Amarelo sob plantio direto (PD) e plantio direto diferenciado (PDD) comparados à mata nativa $(\mathrm{MN})$, em diferentes profundidades. CoimbraMG, 2015

\begin{tabular}{|c|c|c|c|}
\hline \multirow{2}{*}{ Área } & \multicolumn{3}{|c|}{ Profundidades (m) } \\
\hline & $0-0,20$ & & $0,20-0,40$ \\
\hline & & $\mathrm{DS}, \mathrm{g} \mathrm{cm}^{-3}$ & \\
\hline MN & $1,17 \mathrm{aA}$ & & $1,07 \mathrm{aA}$ \\
\hline PD & $1,04 \mathrm{aA}$ & & $1,04 \mathrm{aA}$ \\
\hline \multirow[t]{2}{*}{ PDD } & $1,07 \mathrm{aA}$ & & $1,10 \mathrm{aA}$ \\
\hline & & ADA, $\mathrm{g} \mathrm{kg}^{-1}$ & \\
\hline MN & 0,124 bA & & $0,111 \mathrm{bA}$ \\
\hline PD & $0,268 \mathrm{aA}$ & & $0,178 \mathrm{aB}$ \\
\hline \multirow[t]{2}{*}{ PDD } & $0,260 \mathrm{aA}$ & & $0,211 \mathrm{aB}$ \\
\hline & & IF, $\%$ & \\
\hline MN & 99,9 aA & & 99,9 aA \\
\hline PD & 99,9 aA & & 99,9 aA \\
\hline \multirow[t]{2}{*}{ PDD } & 99,9 aA & & $99,9 \mathrm{aA}$ \\
\hline & & $\mathrm{CC}, \mathrm{g} \mathrm{kg}^{-1}$ & \\
\hline MN & $0,335 \mathrm{cA}$ & & $0,299 \mathrm{cB}$ \\
\hline PD & $0,417 \mathrm{bB}$ & & $0,453 \mathrm{bA}$ \\
\hline \multirow[t]{2}{*}{ PDD } & $0,458 \mathrm{aB}$ & & $0,482 \mathrm{aA}$ \\
\hline & & PMP, $\mathrm{g} \mathrm{kg}^{-1}$ & \\
\hline MN & $0,213 \mathrm{cA}$ & & $0,198 \mathrm{bB}$ \\
\hline PD & $0,243 \mathrm{bB}$ & & $0,259 \mathrm{aA}$ \\
\hline \multirow[t]{2}{*}{ PDD } & $0,256 \mathrm{aB}$ & & $0,268 \mathrm{aA}$ \\
\hline & & $\mathrm{CAD}, \mathrm{g} \mathrm{kg}^{-1}$ & \\
\hline MN & $0,122 \mathrm{cA}$ & & $0,101 \mathrm{bB}$ \\
\hline PD & $0,174 \mathrm{bA}$ & & $0,194 \mathrm{aA}$ \\
\hline \multirow[t]{2}{*}{ PDD } & $0,201 \mathrm{aA}$ & & $0,214 \mathrm{aA}$ \\
\hline & & Argila total, $\mathrm{g}$ & \\
\hline MN & 642 & & 636 \\
\hline PD & 653 & & 679 \\
\hline \multirow[t]{2}{*}{ PDD } & 676 & & 650 \\
\hline & & Silte, $\mathrm{g} \mathrm{kg}^{-1}$ & \\
\hline $\mathrm{MN}$ & 94 & & 87 \\
\hline PD & 96 & & 87 \\
\hline \multirow[t]{2}{*}{ PDD } & 97 & & 93 \\
\hline & & Areia, $\mathrm{g} \mathrm{kg}^{-1}$ & \\
\hline $\mathrm{MN}$ & 264 & & 277 \\
\hline PD & 251 & & 234 \\
\hline PDD & 227 & & 257 \\
\hline
\end{tabular}

Os valores seguidos da mesma letra minúscula na coluna e maiúscula para as profundidades não diferem estatisticamente pelo teste Tukey, a $5 \%$ de probabilidade.

Demonstrando que este ambiente reteve mais água logo após a drenagem natural. $\mathrm{O}$ fato da $\mathrm{MN}$ apresentar menor valor de $\mathrm{CC}$ se deve normalmente a macroporosidade do solo sob mata ser expressivamente maior do que nos solos cultivados (Luciano et al., 2010). Independentemente do manejo adotado, os ambientes cultivados apresentaram maior $\mathrm{CC}$ em comparação à $\mathrm{MN}$, na profundidade $0,20-0,40 \mathrm{~m}$. $\mathrm{O}$ aumento da $\mathrm{CC}$ em profundidade no solo está 
de acordo com o comportamento normal desta variável uma vez que a microporosidade tende a aumentar com a profundidade. Figueiredo et al. (2009) observaram menor capacidade de retenção de água no solo sob Cerrado nativo em relação ao cultivado com milho em SPD, nas duas profundidades avaliadas, o que se atribui à menor DS, conferindo maior porosidade total e macroporosidade, influenciando positivamente a condutividade hidráulica, infiltração e a redistribuição de água no perfil do solo de modo mais uniforme.

Para a variável PMP, observou-se diferença significativa entre os ambientes, com maiores valores para PDD na camada $0-0,20 \mathrm{~m}$. Já na camada $0,20-0,40 \mathrm{~m}$, tal variável não se diferenciou nos solos com PD e PDD, observando-se maior retenção de água nesta camada ao contrário da $\mathrm{MN}$ (Tabela 2), o que se explica pela maior microporosidade em profundidade no solo. O PMP representa o teor de umidade no solo abaixo do qual a planta não conseguirá retirar água na mesma intensidade com que ela transpira. Isto aumenta a cada instante a deficiência de água na planta, o que a levará à morte, caso tal deficiência não seja suprida pela irrigação (Bernardo et al., 2006) ou precipitação. Sales et al. (2016) não observaram diferença para o PMP de um Latossolo Vermelho-Amarelo cultivado no sistema de plantio direto com diferentes plantas de sucessão quando comparado à mata nativa, nas diferentes profundidades.

No que se refere à CAD, houve diferença estatística entre as áreas na profundidade $0-0,20$ $\mathrm{m}$, com maior disponibilidade de água para as plantas nos solos sob PDD e PD uma vez que a matéria orgânica pode ter propiciado maior volume de mesoporos nestes solos não em virtude do seu teor, mas provavelmente pela diferença da matéria orgânica existente na MN e nas áreas de PDD e PD. Na mata, a maior parte da matéria orgânica se encontra em estágio avançado de decomposição, apresentando alto grau de humificação, exercendo, portanto, maior efeito na estabilidade de agregados do solo, tendendo maior formação de macroporos, ao contrário, do que se verifica nas áreas agrícolas. Já na profundidade 0,20-0,40 m, a quantidade de água disponível não se diferiu nos solos sob plantio direto, apresentando maiores valores em relação à $\mathrm{MN}$. Apenas a MN apresentou diferença significativa entre profundidades, registrando maior disponibilidade de água para as plantas na camada menos profunda (Tabela 2). Diferentemente dos resultados verificados para PD e PDD, entre profundidades, Costa et al. (2013) verificaram maior disponibilidade de água nos horizontes superficiais, com mais matéria orgânica, em comparação aos subsuperficiais, comprovando a importância da matéria orgânica na retenção e disponibilidade de água, trabalhando com 44 perfis de solo em áreas de diferentes regiões do Estado de Santa Catarina e com diferentes coberturas vegetais. De forma geral, a MOS pode reter até vinte vezes sua massa em água (Stevenson, 1994). Sales et al. (2016) não encontraram diferença para a água disponível de um Latossolo Vermelho-Amarelo entre o sistema de plantio direto e de preparo convencional do solo, com diferentes plantas de sucessão, e a mata nativa, nas profundidades avaliadas.

A área em estudo apresentou solos de classe textural muito argilosa, evidenciando a condição original do mesmo (Tabela 2). De acordo com Dalmago et al. (2009) a textura do solo não é significativamente afetada por diferentes sistemas de manejo.

\section{Conclusões}

Recomenda-se o uso do solo em sistema de plantio direto e em sistema de plantio direto diferenciado uma vez que apresentaram efeitos químicos e físicos similares ao mesmo solo com cobertura vegetal de mata nativa, devendo-se realizar periodicamente o monitoramento das características químicas e físicas destas áreas agrícolas.

\section{Referências}

ALMEIDA, R.F.; MACHADO, H.A.; MARTINS, F.P.; QUEIROZ, I.D.S.; TEIXEIRA, W.G.; MIKHAEL, J.E.R.; BORGES, E.M. Correlação do tamanho e distribuição dos agregados em Latossolos Amarelo da região do Triângulo Mineiro em diferentes ambientes. Bioscience Journal, v.30, p.1325-1334, 2014.

ANDRADE, R.S.; STONE, L.F.; SILVEIRA, P.M. Culturas de cobertura e qualidade física de um Latossolo em plantio direto. Revista Brasileira de Engenharia Agrícola e Ambiental, v.13, p.411-418, 2009.

ANGHINONI, I. Fertilidade do solo e seu manejo em sistema plantio direto. In: NOVAIS, R.F.; ALVAREZ V., V.H.; BARROS, N.F.; FONTES, R.L.; CANTARUTTI, R.B.; NEVES JCL (Eds.) Fertilidade do Solo. Viçosa, SBCS. 2007. p. 873928.

$\begin{array}{llrr}\text { BARBOSA, } & \text { J.M.; } & \text { REZENDE, } & \text { C.F.A.; } \\ \text { LEANDRO, } & \text { W.M. } & \text { RATKE, } & \text { R.F; }\end{array}$ FERNANDES, E.P. Micronutrient application and residual effect on corn production in a no-tillage 
system. Semina: Ciências Agrárias, v.33, p.2187-2198, 2012.

BERNARDO, S.; SOARES, A.A.; MANTOVANI, E.C. Água no solo. O solo como um reservatório. In: BERNARDO, S.; SOARES, A.A.; MANTOVANI, E.C. (Eds.) Manual de Irrigação. Viçosa, MG: UFV. 2006. p.15-44.

CALEGARI, A.; TIECHER, T.; HARGROVE, W.L.; RALISCH, R.; TESSIER, D.; TOURDONNET, S.; GUIMARÃES, M.F.; SANTOS, D.R. Long-term effect of different soil management systems and winter crops on soil acidity and vertical distribution of nutrients in a Brazilian Oxisol. Soil \& Tillage Research, v.133, p.32-39, 2013.

CAMPOS, L.P.; LEITE, L.F.C.; MACIEL, G.A.; IWATA, B.F.; NÓBREGA, J.C.A. Atributos químicos de um Latossolo Amarelo sob diferentes sistemas de manejo. Pesquisa Agropecuária Brasileira, v.46, p.1681-1689, 2011.

CARNEIRO, C.E.A.; MELÉM JÚNIOR, N.J.; AZEVEDO, M.C.B.; ANDRADE, E.A.; KOGUISHI, M.S.; DIEHL, R.C.; RICCE, W.S.; PASSARIN, A.L.; VAZ, R.H.M.; STELMACHUK, T.L.L.; GUIMARÃES, M.F.; RALISCH, R. Efeitos dos sistemas de manejo sobre o carbono orgânico total e carbono residual de um latossolo vermelho eutroférrico. Semina: Ciências Agrárias, v.30, p.5-10, 2009.

CORREIA, N.M.; DURIGAN, J.C. Culturas de cobertura e sua influência na fertilidade do solo sob sistema de plantio direto (SPD). Bioscience Journal, v.24, p.20-31, 2008.

COSTA, A.; ALBUQUERQUE, J.A.; COSTA, A.; PÉRTILE, P.; SILVA, F.R. Water retention and availability in soils of the state of Santa Catarina-Brazil: effect of textural classes, soil classes and lithology. Revista Brasileira de Ciência do Solo, v.37, p.1535-1548, 2013.

CUNHA, E.Q.; STONE, L.F.; MOREIRA, J.A.A.; FERREIRA, E.P.B.; DIDONET, A.D.; LEANDRO, W.M. Sistemas de preparo do solo e culturas de cobertura na produção orgânica de feijão e milho. I - Atributos físicos do solo. Revista Brasileira de Ciência do Solo, v.35, p.589-602, 2011.

DALMAGO, G.A.; BERGAMASCHI, H., BERGONCI, J.I.; KRUGER, C.A.M.B.; COMIRAN, F.; HECKLER, B.M.M. Retenção e disponibilidade de água às plantas em solo sob plantio direto e preparo convencional. Revista Brasileira de Engenharia Agrícola e Ambiental, v.13, p.855-864, 2009.
EMBRAPA - Empresa Brasileira de Pesquisa Agropecuária. Manual de métodos de análise de solo. Rio de Janeiro: CNPS/EMBRAPA, 1997. 212p.

EMBRAPA - Empresa Brasileira de Pesquisa Agropecuária. Sistema brasileiro de classificação de solos. $3^{\mathrm{a}}$ ed. Brasília: Embrapa, 2013.353p.

FEBRAPDP - Federação Brasileira de Plantio Direto na Palha e Irrigação. Evolução Área do Sistema Plantio Direto no Brasil. Disponível em:

$<$ http://febrapdp.org.br/download/PD_Brasil_201

3.jpg $>$. Acessado em: 25 de abril de 2016.

FIGUEIREDO, C.C.; SANTOS, G.G.; PEREIRA, S.; NASCIMENTO, J.L.; ALVES JÚNIOR, J. Propriedades físico-hídricas em Latossolo do Cerrado sob diferentes sistemas de manejo. Revista Brasileira de Engenharia Agrícola e Ambiental, v.13, p.146-151, 2009.

FRAZÃO, L.A.; PÍCCOLO, M.C.; FEIGL, B.J.; CERRI, C.C.; CERRI, C.E.P. Propriedades químicas de um Neossolo Quartzarênico sob diferentes sistemas de manejo no Cerrado matogrossense. Pesquisa Agropecuária Tropical, v.43, p.641-648, 2008.

JAKELAITIS, A.; SILVA, A.A.; SANTOS, J.B.; VIVIAN, R. Qualidade da camada superficial de solo sob mata, pastagens e áreas cultivadas. Pesquisa Agropecuária Tropical, v.38, p.118127, 2008.

JORDAN, A.; ZAVALA, L.M.; GIL, J. Effects of mulching on soil physical properties and runoff under semi-arid conditions in Southern Spain. Catena, v.81, p.77-85, 2010.

LOURENTE, E.R.P.; MERCANTE, F.M.; ALOVISI, A.M.T.; GOMES, C.F.; GASPARINI, A.S.; NUNES, C.M. Atributos microbiológicos, químicos e físicos de solo sob diferentes sistemas de manejo e condições de Cerrado. Pesquisa Agropecuária Tropical, v.41, p.20-28, 2011.

LUCIANO, R.V.; BERTOL, I.; BARBOSA, F.T.; KURTZ, C.; FAYAD, J.A. Propriedades físicas e carbono orgânico do solo sob plantio direto comparado à mata natural, num Cambissolo Háplico. Revista de Ciências Agroveterinárias, v.9, p.09-19, 2010.

MACHADO, L.V.; RANGEL, O.J.P.; MENDONÇA, E.S.; MACHADO, R.V.; FERRARI, J.L. Fertilidade e compartimentos da matéria orgânica do solo sob diferentes sistemas de manejo. Coffee Science, v.9, p.289-299, 2014. 
MALAVOLTA, E. Manual de nutrição mineral de plantas. $1^{\mathrm{a}}$ ed. São Paulo: Agronômica Ceres, 2006. $631 \mathrm{p}$.

MARASCA, I.; GONÇALVES, F.C.; MORAES, M.H.; BALLARIN, A.W.; GUERRA, S.P.S.; LANÇAS, K.P. Propriedades físicas de um Nitossolo Vermelho em função dos sistemas de uso e manejo. Revista Brasileira de Engenharia Agrícola e Ambiental, v.17, p.1160-1166, 2013.

MARTÍNEZ, E.; FUENTES, J.P.; PINO, V.; SILVA, P.; ACEVEDO, E. Chemical and biological properties as affected by no-tillage and conventional tillage systems in an irrigated Haploxeroll of Central Chile. Soil \& Tillage Research, v.126, p.238-245, 2013.

MATIAS, M.C.B.; SALVIANO, A.A.C.; LEITE, L.F.C.; GALVÃO, S.R.S. Propriedades químicas em Latossolo Amarelo de Cerrado do Piauí sob diferentes sistemas de manejo. Revista Ciência Agronômica, v.40, p.356-362, 2009.

MAZURANA, M.; LEVIEN, R.; MÜLLER, J.; CONTE, O. Sistemas de preparo de solo: alterações na estrutura do solo e rendimento das culturas. Revista Brasileira de Ciência do Solo, v.35, p.1197-1206, 2011.

NICOLOSO, R.S.; LOVATO, T.; AMADO, T.J.C.; BAYER, C.; LANZANOVA, M.E. Balanço do carbono orgânico no solo sob integração lavoura-pecuária no Sul do Brasil. Revista Brasileira de Ciência do Solo, v.32, p.425-2433, 2008.

OLIVEIRA, D.M.S.; LIMA, R.P.; VERBURG, E.E.J. Qualidade física do solo sob diferentes sistemas de manejo e aplicação de dejeto líquido suíno. Revista Brasileira de Engenharia Agrícola e Ambiental, v.19, p.280-285, 2015.

PEREIRA JUNIOR, E.B.; HAFLE, O.M.; GOMES, E.M.; ANDRADE, M.E.L.; SANTOS, L.G.; DELFINO, F.I. Avaliação dos atributos físicos do solo submetido à práticas de manejo, em Agroecossistemas do semi-árido. Revista Acta Tecnológica, v.5, p.43-51, 2010.

RAMOS, B.Z.; PAIS, P.S.M.; FREITAS, W.A.; D. JUNIOR, M.S. Avaliação dos atributos físicohídricos em um LatossoloVermelho distroférrico sob diferentes sistemas de manejo-Lavras/Minas Gerais/Brasil. Revista de Ciências Agrárias, v.36, p.340-346, 2013.

SALES, R.P.; PORTUGAL, A.F.; MOREIRA, J.A.A.; KONDO, M.K.; PEGORARO, R.F. Qualidade física de um Latossolo sob plantio direto e preparo convencional no semiárido.
Revista Ciência Agronômica, v.47, p.429-438, 2016.

SCHERER E.E.; NESI, C.N.; MASSOTTI, Z. Atributos químicos do solo influenciados por sucessivas aplicações de dejetos suínos em áreas agrícolas de Santa Catarina. Revista Brasileira de Ciência do Solo, v.34, p.1375-1383, 2010.

SCHERER, E.E.; BALDISSERA, I.T.; NESI, C.N. Propriedades químicas de um latossolo vermelho sob plantio direto e adubação com esterco de suínos. Revista Brasileira de Ciência do Solo, v.31, p.123-131, 2007.

SILVA, F.A.S.; AZEVEDO, C.A.V. Principal Components Analysis in the Software AssistatStatistical Atten dance. In: WORLD CONGRESS ON COMPUTERS IN AGRICULTURE, 7, RenoNV-USA: American Society of Agricultural and Biological Engineers, 2009.

SOUSA, D.M.G.; MIRANDA, L.N.; OLIVEIRA, A.S. Acidez do solo e sua correção. In: NOVAIS, R.F.; ALVAREZ V., V.H.; BARROS, N.F.; FONTES, R.L.; CANTARUTTI, R.B.; NEVES, J.C.L. (Eds.) Fertilidade do Solo. $1^{\text {a }}$ ed. Viçosa, SBCS, 2007. p.205-274.

STEVENSON, F.J. Humus chemistry: Genesis, composition and reactions. $2^{\mathrm{a}}$ ed. New York, John Wiley \& Sons, 1994. 443p.

TORRES, J.L.R.; PEREIRA, M.G.; FABIAN, A.J. Produção de fitomassa por plantas de cobertura e mineralização de seus resíduos em plantio direto. Pesquisa Agropecuária Brasileira, v.43, p.421-428, 2008.

VITA, P.; PAOLO, E.D.; FECONDO, G.; FONZO, N.D.; PISANTE, M. No-tillage and convencional tillage effects on durun wheat yield, grain quality and soil moisture content in southern Italy. Soil \& Tillage Research, v.92, p.69-787, 2007.

WASTOWSKI, A.D.; ROSA, G.M.; CHERUBIN, M.R.; RIGON, J.P.G. Caracterização dos níveis de elementos químicos em solo, submetido a diferentes sistemas de uso e manejo, utilizando espectrometria de fluorescência de raios-X por energia dispersiva (EDXRF). Química Nova, v.33, p.1449-1452, 2010.

WENDLING, B.; VINHAL-FREITAS, I.C.; OLIVEIRA, R.C.; BABATA, M.M.; BORGES, E.N. Densidade, agregação e porosidade do solo em áreas de conversão do Cerrado em floresta de pinus, pastagem e plantio direto. Bioscience Journal, v.28, p.256-265. 2012. 
WYNGAARD, N.; ECHEVERRÍA, H.E.; ROZAS, H.R.S.; DIVITO, G.A. Fertilization and tillage effects on soil properties and maize yield in a Southern Pampas Argiudoll. Soil \& Tillage Research, v.119, p.22-30, 2012.

YAGI, R.; BITTENCOURT, H.V.H.; FIDALSKI, J.; CASSOL, L.C.; CONSTANTY, H.F.P-H. Diagnóstico de atributos químicos e físicos de solos sob plantio direto em propriedades agrícolas familiares do Sudoeste do Paraná. Synergismus scyentifica UTFPR, v.6, p.1-10, 2011.

ZANÃO JÚNIOR, L.A.; LANA, R.M.Q.; GUIMARÃES, E.C. Variabilidade espacial do $\mathrm{pH}$, teores de matéria orgânica e micronutrientes em profundidades de amostragem num Latossolo Vermelho sob semeadura direta. Ciência Rural, v.37, p.1000-1007, 2007.

ZANETTE, S.V.; SAMPAIO, S.C.; SILVESTRE, M.G.; BOAS, M.A.V.; URIBE-OPAZO, M.A.; QUEIROZ, M.M.F. Análise espacial da umidade do solo cultivado com soja sob dois sistemas de manejo. Revista Brasileira de Engenharia Agrícola e Ambiental, v.11, p.239-247, 2007. 